Peter Botticelli, Martha R. Mahard, and Michèle V. Cloonan. Libraries, Archives, and Museums Today: Insights from the Field. Lanham, MD: Rowman \& Littlefield, 2019. Paper, 198p. \$33.00 (ISBN 978-1-5381-2555-7).

For more than a decade, libraries, archives, and museums (LAM) have been discussing digital access to collections and digital asset management. Coordinating successful interfaces for users, who also may be internal to an organization, requires multiple areas of expertise: vision from administrators; content and context from archivists, librarians, and curators; and technical skills from catalogers, specialists in digital curation, and web developers. Rarely can effective systems be developed by just one of these specialties. It takes collaboration, resources, and navigation of the "languages" of each separate, but related, discipline. Practitioners in these fields know that working together for such projects can be challenging, despite similar goals of preserving and providing access to historical materials. In Libraries, Archives, and Museums Today: Insights from the Field, authors Peter Botticelli, Martha R. Mahard, and Michèle V. Cloonan present 14 case studies that document the current issues, successes, and failures related to collaboration around technology at a number of diverse cultural institutions, as well as overall challenges in the digital age.

The authors and contributors are mostly associated with Simmons University School of Library and Information Science in Boston. Botticelli, Mahard, and Cloonan (dean emerita) are professors in the school. Botticelli and Cloonan coordinate the Cultural Heritage Informatics (CHI) program, which "examines the nexus of information and computing technology in cultural heritage institutions" (xi). Many of the contributors have connections with Simmons' library program: as graduates, instructors, internship supervisors, employers of their graduates, or professional colleagues who assisted with creating the CHI program. The authors' perspectives as educators prompted them to develop this book, presumably for pedagogical purposes, although also for professionals, and to add to the libraries, archives, and museums (LAM) literature.

The case studies are organized in five parts: Digital Strategies; Collaboration within and across Institutions; Strategic Use of Resources; Institutions in Transition; and Culturally Sensitive Materials. Each case follows a similar format, including an "Interviews" paragraph that explains why the authors chose this institution, anticipated outcomes of their research, and those interviewed; a history of the organization; and an exposition of the salient points that arose from the interviews, which were conducted during the last 10 years. The institutions and organizations selected range from the American Antiquarian Society, to the American Archive of Public Broadcasting, to Historic New England; more than half of them are located in Massachusetts. Outliers include the Maine Memory Network, Cornell University Library Division of Rare and Manuscript Collections, the Museum of Modern Art, 
and, internationally, the Victoria and Albert Museum in England and the National Library of Australia. One organization is anonymized.

Of the studies, I found the chapter "The National Library of Australia: Digital Assets as a Driver for Change in a National Library" to be the most refreshing and compelling. It describes a successful collaboration among a library, archives, and museum through — among other efforts—-reframing traditional digital access and preservation workflows to embrace a "whole life cycle" process for digital objects and fostering innovation throughout the organization. Through the study of another institution with a long history of digital activity, the Boston Public Library, I gained a broad perspective of their efforts about in-house digitization, as well as outreach on Flickr and their participation in multi-institution digital portals. In a study of the Peabody Museum of Archeology and Ethnology at Harvard University, I was intrigued to learn how they work across LAM boundaries to digitize and describe culturally sensitive content in their museum archives. Many of the other cases remind us that most organizations - great and small, and across the LAM spectrumexperience trial-and-error approaches to digital access and collaboration.

Given the authors' strong backgrounds and interests in digital matters in the library and archives disciplines, as well as the historic focus of LAM literature on digital "convergence," I was not surprised to find that many of the case studies focused on digital issues. All of the questions asked of interviewees about digital topics are found in appendix A, whether about management, workflows, future plans regarding digital strategies, or institutional support for digitization or digital assets. What was surprising were the cases in the "Institutions in Transition" section. These three cases related to library and museum closures or changes in the relationships of LAMs to their parent organizations, with only tangential, if any, connection to technology. The chapters were insightful, however, in showing how LAMs and their goals suffer when one part of the relationship is not supported. Presumably, these powerful stories developed from the initial interviews.

\section{INDEX TO ADVERTISERS}

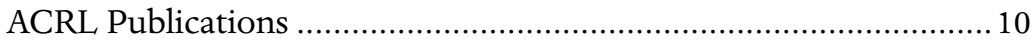

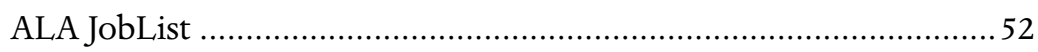

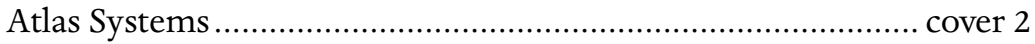

Bruce McKittrick Rare Books.............................................. cover 3

Kelmscott Bookshop .................................................................... 8

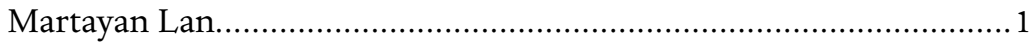

Philadelphia Rare Books \& Manuscripts ............................... cover 4

Rulon-Miller Books .................................................................... 4 
The extensive research about digital issues at a range of organizations is a significant contribution to the LAM literature, which does not have many book-length publications devoted to case studies. The research and clear writing are the publication's strength. Even with multiple authors, the case studies are uniformly well written and effective in their detail, with many direct quotes from interviewees. The studies provide a snapshot in time about the institutions and allow for future research about other institutions in other regions.

The major weakness of this publication is, in a word, conclusions. The book's most substantial interpretive work is done in the introductory matter, and that is really all that is necessary to present the cases, from which readers will draw their own conclusions. The last section of each study is called "Conclusion" but, in most instances, is merely a summary of the case. The final chapter, "Conclusion," introduces new themes not previously referenced, followed by one-paragraph case study summaries and suggestions about what readers could learn from them. These summaries would have served better as chapter abstracts at the beginning of each case study, allowing the authors to eliminate the so-called "conclusion" at the end of each chapter.

This publication will be a valuable resource for graduate students who plan to work in libraries, archives, museums, or the public history field. Students can see behind the scenes to become familiar with current issues and learn the histories of a selection of cultural heritage institutions. For professionals in the LAM fields, the book provides the ability to compare decision-making paths with one's own situation and to learn about the trials and successes of multiple types of organizations.-Greta Reisel Browning, Appalachian State University

Laura A. Millar. A Matter of Facts: The Value of Evidence in an Information Age.

Chicago, IL: ALA Neal-Schuman, 2019. Paperback, 192p. \$44.99 (ISBN 9780838917718).

The postmodern and post-truth world we live in might have reached its zenith. Written for the general public and not specifically information professionals, Laura A. Millar's A Matter of Facts: The Value of Evidence in an Information Age grapples with the definitions of data, facts, evidence, and truth and how these parts of information are used and abused in modern society. This volume is the first in the Archival Futures series, jointly published by the Society of American Archivists (SAA) and ALA Neal-Schuman, which will demonstrate "how the preservation and stewardship of the archival record is a collective effort that underpins and supports democratic societies and institutions" (viii). Dr. Millar is an obvious choice to lead the series, given her notable career as an independent consultant and her numerous publications on creating and maintaining archives during the last 30 years. Her 